\title{
Antenatal Magnesium Sulfate Exposure and Hemodynamically Significant Patent Ductus Arteriosus in Premature Infants
}

\author{
Amna Qasim, MD ${ }^{1}$ Sunil K. Jain, $\mathrm{MD}^{2}$ Ashraf M. Aly, MD ${ }^{3}$ \\ ${ }^{1}$ Department of Pediatrics, University of Texas Medical Branch, \\ Galveston, Texas \\ 2 Division of Neonatology, University of Texas Medical Branch, \\ Galveston, Texas \\ ${ }^{3}$ Division of Pediatric Cardiology, University of Texas Medical Branch, \\ Galveston, Texas \\ Address for correspondence Amna Qasim, MD, Department of \\ Pediatrics, University of Texas Medical Branch, 301 University \\ Boulevard, Galveston, TX-77555 (e-mail: amnahqasim@gmail.com). \\ Am J Perinatol Rep 2019;9:e353-e356.
}

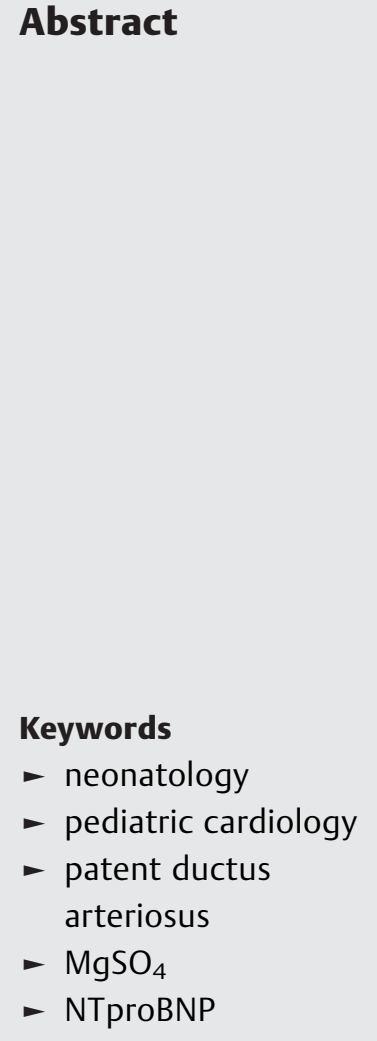

Objective The use of antenatal magnesium sulfate $\left(\mathrm{MgSO}_{4}\right)$ has been associated with neuroprotective effects. One of its' proposed mechanisms of action includes antagonism of calcium channels. Calcium influx is important for closure of ductus arteriosus. We hypothesized that antenatal $\mathrm{MgSO}_{4}$ exposure may be associated with an increased risk of hemodynamically significant patent ductus arteriosus (HsPDA) in premature infants (PI).

Study Design A prospective cohort study conducted in two parts. $\mathrm{PI}$ ( $<32$ weeks and $<1,500 \mathrm{~g}$ ) were recruited $(n=105)$. All infants had Echocardiograph (ECHO; within 3 days) and blood samples drawn at the same time for B-type natriuretic peptide (BNP; part 1) and NTproBNP (N-terminal pro BNP; part 2) measurements. HsPDA was defined as a PDA diameter $>1.5 \mathrm{~mm}$ and BNP levels $>40 \mathrm{pg} / \mathrm{mL}$ or NTproBNP $>10,200 \mathrm{pg} / \mathrm{mL}$. Infants were divided into two groups based on antenatal $\mathrm{MgSO}_{4}$ exposure. Data were analyzed using SPSS 23. Difference in baseline characteristics and antenatal steroid use in the two groups was analyzed. A matched group analysis was performed to adjust for the difference in the numbers between the two groups. A $p$-value $<0.05$ was considered significant.

Results There was no significant difference seen in baseline characteristics or use of antenatal steroids in exposed versus unexposed $(n=95$ vs. $n=10)$. There was a significant negative correlation between antenatal $\mathrm{MgSO}_{4}$ exposure and $\mathrm{HsPDA}$ in $\mathrm{PI}$ $(p \leq 0.05)$. However, this association was not significant after matched group analysis. Conclusion Antenatal $\mathrm{MgSO}_{4}$ exposure is not associated with an increased risk of HsPDA. It may be associated with a decreased likelihood of HsPDA.
Magnesium is an abundant cation in the body that plays an important role in several intracellular mechanisms. ${ }^{1}$ Studies have suggested a neuroprotective effect of magnesium sulfate $\left(\mathrm{MgSO}_{4}\right)$, with reductions in cerebral palsy rates in survivors. ${ }^{2,3}$ The available evidence from various large randomized controlled trials suggests that $\mathrm{MgSO}_{4}$ given before anticipated early preterm birth reduces the risk of cerebral palsy in surviving infants. ${ }^{4-6}$ The neuroprotective effects of $\mathrm{MgSO}_{4}$ for the fetus are due to various proposed mechanisms, such as effects on cellular metabolism, decreased cell death by inhibition of calcium influx-mediated neuronal apoptosis, decreased cell injury by reduction in proinflammatory received

June 6, 2019

accepted after revision

July 2, 2019
DOI https://doi.org/

10.1055/s-0039-3400316. ISSN 2157-6998.
Copyright $\odot 2019$ by Thieme Medical Publishers, Inc., 333 Seventh Avenue, New York, NY 10001, USA. Tel: +1(212) 584-4662.
License terms

(요 (1) $\Theta$ 
cytokines, and regulation of blood flow to the brain by inhibition of vascular voltage-depended calcium channels. ${ }^{1}$ The Committee on Obstetric Practice and the Society for Maternal-Fetal Medicine recommends that physicians electing to use $\mathrm{MgSO}_{4}$ for fetal neuroprotection should develop specific guidelines regarding inclusion criteria, treatment regimens, concurrent tocolysis, and monitoring in accordance with one of the larger trials. In our maternal-fetal medicine division, it is standard of practice to administer $\mathrm{MgSO}_{4}$ for neuroprotection for preterm deliveries $<32$ weeks. The incidence of $\mathrm{MgSO}_{4}$ exposure in preterm deliveries $<32$ weeks is $99 \%$. The usual duration of antenatal $\mathrm{MgSO}_{4}$ for neuroprotection is the standard 12 hours with a loading dose of $4 \mathrm{~g}$ with a continuous of $2 \mathrm{~g} / \mathrm{hr}$. After 12 hours, it is discontinued and the patient is managed expectantly. $\mathrm{MgSO}_{4}$ may be restarted if patient makes cervical change is expected to deliver in the next 6 hours.

Patent ductus arteriosus (PDA) is commonly seen in premature infants $(\mathrm{PI}) .^{7}$ Patency of ductus arteriosus is mediated by smooth muscle relaxation from the activation of $\mathrm{G}$-protein coupled prostaglandin receptors (PGE2). The postnatal decline in the levels of PGE2/prostacyclin (PCI) and increase in oxygen tension leads to calcium influx mediated ductal constriction. ${ }^{7}$ A large PDA with increased left to right shunting of blood has significant hemodynamic consequences: compromised systemic perfusion, pulmonary overflow, and, eventually, heart failure. A hemodynamically significant PDA (HsPDA) is associated with intraventricular hemorrhage (IVH), bronchopulmonary dysplasia (BPD), necrotizing enterocolitis (NEC), congestive heart failure (CHF), and increased mortality. ${ }^{8}$

This study was based on the hypothesis that by antagonizing the influx of calcium required for ductal constriction, the use of antenatal $\mathrm{MgSO}_{4}$ may increase the risk of HsPDA in PI.

\section{Materials and Methods}

This is a prospective cohort study conducted between 2011 and 2016. It was a part of two larger studies that were conducted to evaluate a relationship between PDA and cardiac biomarkers. After institutional review board's (IRB's) approval and parental permission, PIs ( $<32$ weeks and $<1,500 \mathrm{~g}$ ) born at the University of Texas Medical Branch in Galveston, were recruited $(n=105)$. Infants with significant congenital or chromosomal anomalies and those born at outside hospitals were excluded. Maternal and infant data were collected from electronic medical records.

Echocardiograph (ECHO): all infants had ECHO done within first 3 days of life. ECHO was performed by trained pediatric ECHO technician by using the Philips iE33 (Philips North America Corporation, Andover, MA, USA) ultrasound machine. In each ECHO study, we recorded and analyzed PDA diameter, left atrial to aortic root (LA/AO) ratio, and ejection fraction using Simpson's biplane method. The diameter of PDA was determined in the two-dimensional parasternal short-axis view. PDA diameter was measured at the junction of PDA and the main pulmonary artery. The left to right ductal flow was confirmed with the color Doppler ultrasound scanning. A two-dimensional parasternal long-axis view was obtained for the assessment of the diameter of the LA in systole and AO diameter, and LA/AO ratio was calculated. All ECHO data were saved and was analyzed by a pediatric cardiologist. Both the ECHO technician and the pediatric cardiologist were blinded to the study groups.

B-type natriuretic peptide (BNP) and N-terminal pro BNP (NTproBNP) measurement: in the first study, we measured BNP levels on day 3 of life $(n=37)$ and in the second study, NTproBNP levels were measured $(n=68)$. Arterialized capillary by heel prick or umbilical arterial blood sample $(0.5 \mathrm{~mL})$ was collected in chilled Ethylenediamine tetraacetic acid (EDTA) tubes within 3 hours of ECHO. Blood sample was centrifuged at $3,000 \mathrm{rpm}$ for 15 minutes at $4^{\circ} \mathrm{C}$. Separated plasma was stored at $-80^{\circ} \mathrm{C}$ until BNP analysis of all collected samples. The BNP assay was performed using the Triage BNP kit (Bio site Diagnostic, Sa Diego, CA), a fluorescence immunoassay. The assay has a measurable range 5 to $5,000 \mathrm{pg} / \mathrm{mL}$. The estimated coefficient of variation for the assay is 9.2 to $11.4 \%$. NTproBNP was measured in batch by routine immune-assay analysis on the Cobas e601 platform (Roche Diagnostics, Indianapolis, IN) at the department of Clinical Biochemistry, University of Texas Medical Branch in Galveston. Electro chemiluminescent sandwich enzyme linked immunoabsorbant assay were used. The Elecsys (Roche Diagnostics, Indianapolis, IN) proBNP II (a product of Roche Diagnostics) quantitative assay has a lower and upper detection limit of 5 and $70,000 \mathrm{pg} / \mathrm{mL}$.

Criteria for HsPDA: the definition of a HsPDA was based on previously established criteria and was defined by the presence of PDA diameter $>1.5 \mathrm{~mm}^{8}$ and BNP levels $>40 \mathrm{pg} / \mathrm{dL}$ (92\% sensitivity and 46\% specificity) or NTproBNP levels $>10,200 \mathrm{pg} / \mathrm{dL}$ (100\% sensitivity and $91 \%$ specificity for diagnosis of HsPDA). ${ }^{9}$

Study groups: Magnesium (Mg) group ( $n=95)$-infants who were exposed to antenatal $\mathrm{MgSO}_{4}$ for neuroprotection, and control group $(n=10)$-infants who were not exposed to antenatal $\mathrm{MgSO}_{4}$.

\section{Clinical Data}

Clinical medical data were collected from electronic medical records. We checked for difference in antenatal steroid use in the two groups and used logistic regression correcting for gestational age and birth weight. Other risk factors, including intraventricular hemorrhage, evaluated at 7 days of life using the Papile's classification, ${ }^{10}$ bronchopulmonary dysplasia (BPD) defined as persistent requirement of oxygen at and beyond 36 weeks of life, ${ }^{11}$ and necrotizing enterocolitis (NEC) with radiographic evidence of pneumatosis intestina$\operatorname{lis}^{12}$ were also reviewed. Infants with PDA (any size) were followed to see how many ended up requiring treatment (medical or surgical).

\section{Selection of Subjects}

Infants with no antenatal $\mathrm{MgSO}_{4}$ exposure $(n=10)$ were randomly matched with infants for gestational age, birth weight, and gender with the same number of infants with antenatal $\mathrm{MgSO}_{4}$ exposure for further analysis. These infants were born within 6 months of each other. Matching was performed by an investigator who was blinded to all other 
infant characteristics. To compare the sickness in the groups, the clinical risk index for babies (CRIB II) scores was calculated for all the matched infants. ${ }^{13}$ The same outcome measures were studied again in the matched groups.

\section{Statistical Analysis}

Data were analyzed using IBM SPSS version 23 (International Business Machines Corporation, Armonk, New York). Categorical variables were compared using X-test ${ }^{2}$ or Fisher's exact test and variables with normal distribution were compared using one-way analysis of variance (ANOVA). Collinearity was determined using Pearson's correlation coefficient and a regression analysis was performed correcting for birth weight, gestational age, gender, and antenatal steroid use. A $p$-value of $<0.05$ was considered significant.

\section{Results}

- Table 1 shows the baseline characteristics of the two groups $(n=105)$. Pearson's correlation analysis demonstrates a negative correlation between antenatal $\mathrm{MgSO}_{4}$ use and the occurrence of an HsPDA in neonates ( $p \leq$ $0.05)$. There was no significant difference in the use of antenatal steroids between the two groups $(p=0.062)$. Of note, the ejection fraction, mean PDA diameter, mean LA/AO ratio, and requirement for medical versus surgical treatment were not significantly different $(p=0.383,0.063$, and 0.103 , respectively) in the two groups. Increasing gestational age, birth weight, and male gender were all associated with a

Table 1 Baseline characteristics

\begin{tabular}{|c|c|c|c|}
\hline Characteristic & $\begin{array}{l}\text { Antenatal } \\
\text { MG } \\
(n=95)\end{array}$ & $\begin{array}{l}\text { Control } \\
(n=10)\end{array}$ & $p$-Value \\
\hline Birth weight (g) & $1007 \pm 271$ & $1,030 \pm 329$ & 0.81 \\
\hline Sex (male) $n(\%)$ & $48(51)$ & $5(50)$ & 0.61 \\
\hline $\begin{array}{l}\text { Gestational } \\
\text { age (wk) }\end{array}$ & $27.8 \pm 2.3$ & $27.6 \pm 2.5$ & 0.79 \\
\hline \multicolumn{4}{|l|}{ Race $n(\%)$} \\
\hline Hispanic & $36(38)$ & $6(60)$ & \multirow[t]{4}{*}{0.11} \\
\hline Caucasian & $29(30.5)$ & $3(30)$ & \\
\hline African American & $29(30.5)$ & $1(10)$ & \\
\hline Asian & $1(1)$ & $0(0)$ & \\
\hline $\begin{array}{l}\text { Antenatal } \\
\text { steroid use }\end{array}$ & $74(78)$ & $5(50)$ & 0.12 \\
\hline BPD $n(\%)$ & $24(25)$ & $3(30)$ & 0.7 \\
\hline NEC $n(\%)$ & $9(9.5)$ & $1(10)$ & 1.0 \\
\hline $\mathrm{IVH} n(\%)$ & $7(7.4)$ & $2(20)$ & 0.2 \\
\hline HsPDA $n(\%)$ & $12(13)$ & $4(40)$ & 0.04 \\
\hline $\begin{array}{l}\text { PDA } \\
\text { treatment } n(\%)\end{array}$ & $15(16)$ & $4(40)$ & 0.08 \\
\hline
\end{tabular}

Abbreviations: BPD, bronchopulmonary dysplasia; HsPDA, hemodynamically significant patent ductus arteriosus; IVH, intraventricular hemorrhage; NEC, necrotizing enterocolitis; MG, Magnesium sulfate.
Table 2 Matched group analysis

\begin{tabular}{|l|l|l|l|}
\hline Characteristic & $\begin{array}{l}\text { Antenatal } \\
\text { MG }(\boldsymbol{n}=\mathbf{1 0})\end{array}$ & $\begin{array}{l}\text { Control } \\
(\boldsymbol{n}=\mathbf{1 0})\end{array}$ & $p$-Value \\
\hline $\begin{array}{l}\text { Gestational age } \\
(\mathbf{w k}) \text { (mean } \pm \text { SD) }\end{array}$ & $27.6 \pm 2.5$ & $27.6 \pm 2.5$ & 1.00 \\
\hline $\begin{array}{l}\text { Birth weight (g) } \\
(\text { mean } \pm \text { SD) }\end{array}$ & $1,026 \pm 360$ & $1,030 \pm 329$ & 0.98 \\
\hline Sex, male $\boldsymbol{n}(\%)$ & $5(50)$ & $5(50)$ & 0.67 \\
\hline $\begin{array}{l}\text { CRIB II score } \\
(\text { mean } \pm \text { SD) }\end{array}$ & $8.1 \pm 3.6$ & $8.2 \pm 3.2$ & 0.94 \\
\hline HsPDA $\boldsymbol{n}(\%)$ & $3(30)$ & $4(40)$ & 0.5 \\
\hline $\begin{array}{l}\text { PDA Treatment } \\
\boldsymbol{n}(\%)\end{array}$ & $1(10)$ & $5(50)$ & 0.07 \\
\hline $\begin{array}{l}\text { Antenatal } \\
\text { steroid use }\end{array}$ & $3(30)$ & $5(50)$ & 0.32 \\
\hline BPD $\boldsymbol{n}(\%)$ & $2(20)$ & $4(40)$ & 0.31 \\
\hline NEC $\boldsymbol{n}(\%)$ & $1(10)$ & $1(10)$ & 0.76 \\
\hline IVH $\boldsymbol{n}(\%)$ & $2(20)$ & $2(20)$ & 0.71 \\
\hline
\end{tabular}

Abbreviations: BPD, Bronchopulmonary dysplasia; CRIB, Clinical risk index for babies; HsPDA, Hemodynamically significant patent ductus arteriosus; IVH, Intraventricular hemorrhage; NEC, Necrotizing enterocolitis; SD, standard deviation; MG, Magniesum sulfate.

decreased likelihood of HsPDA $(p<0.05)$. Antenatal steroid use not significantly associated with likelihood of HsPDA.

Matched group analysis ( - Table 2 ) showed no significant association between antenatal $\mathrm{MgSO}_{4}$ use and the occurrence of an $\operatorname{HsPDA}(p=0.50)$. Even though more infants in the control group (5/10) required treatment for PDA compared with MG group (1/10), this difference was not significant $(p=0.07)$. There was no significant difference in the gestational age (GA), birth weight (BW), gender, CRIB II scores, and antenatal steroid use in the two groups.

\section{Discussion}

Contrary to our hypothesis that magnesium may increase the risk of an HsPDA by its role as a calcium channel antagonist, the results of our study actually showed a decrease in hemodynamically significant PDA in infants exposed to antenatal $\mathrm{MgSO}_{4}$. Even though this finding was not statistically significant upon conducting a matched group analysis, the number of patients requiring treatment for PDA was lower in the group exposed to magnesium versus control (1/ 10 vs. 5/10). To our knowledge, this is the first reported association of antenatal $\mathrm{MgSO}_{4}$ exposure with HsPDA.

There are limited data in literature about the effects of antenatal $\mathrm{MgSO}_{4}$ on the neonatal cardiovascular system. James et al studied the effect of antenatal $\mathrm{MgSO}_{4}$ use on the cardiovascular system in a cohort study using novel echocardiographic parameters and found that infants who were exposed to antenatal $\mathrm{MgSO}_{4}$ had significantly lower systolic blood pressure (BP) and systemic vascular resistance on day 1 of life but no significant difference on day $2 .^{14}$ Paradisis et al performed a randomized controlled trial to study whether the neuroprotective effects of $\mathrm{MgSO}_{4}$ were secondary to 
cardiovascular changes. ${ }^{15}$ They found significantly higher heart rate and higher incidence of low superior vena cava flow at 10 to 12 hours of life but no significant difference was found at 24 hours of life. They reported an incidental finding of a significantly smaller PDA (0.4 vs. $0.8 \mathrm{~mm}$ ) in the $\mathrm{MgSO}_{4}$ group. This incidental finding, in conjunction to the findings of our study, may point toward a role of magnesium in the closure of the ductus arteriosus. However, given the difficulty in getting echocardiographic measurements of PDA size and the large interobserver variability, it is difficult to make a definite conclusion based on this incidental finding.

The previous studies point toward the role of magnesium in decreasing peripheral vascular resistance via noncompetitive antagonism of inositol triphosphate gated calcium channels. ${ }^{14}$ However, the results of our study could infer that magnesium does not antagonize the calcium channels responsible for mediating ductal constriction. Similar to its elusive mechanism of action in improving neurodevelopmental outcome, our results could be explained by one or more of the many complex intracellular actions of magnesium.

It is a standard of practice at the University of Texas Medical Branch hospital in Galveston to give antenatal $\mathrm{MgSO}_{4}$ for neuroprotection to all pregnant women who are at risk of delivering prior to 32 weeks of gestation. The incidence of $\mathrm{MgSO}_{4}$ exposure in women with preterm deliveries $<32$ weeks is close to $99 \%$ at our institution. These women also receive antenatal steroids for fetal lung maturity. The women who did not receive $\mathrm{MgSO}_{4}$ are likely those who did not have enough time between presentation to the hospital and delivery. To account for the limited sample size and the possible confounding effect of antenatal steroid exposure, we performed a matched group analysis. We did not see a significant difference in the incidence of HsPDA in the matched groups.

The main limitation of our study is the small sample size of the group that was not exposed to antenatal $\mathrm{MgSO}_{4}$. Even though the first part of our study reports a statistically significant finding, it was not significant upon adjusting for numbers and conducting a matched group analysis.

\section{Conclusion}

Exposure to antenatal $\mathrm{MgSO}_{4}$ in PI does not increase the likelihood of HsPDA. It may actually have a protective role in helping with ductal closure, although we do not have sufficient evidence to make that conclusion at this time. Further studies need to be performed to see if these results are reproducible and to look into the association of magnesium with HsPDA.

\section{Funding Details}

No funding or sponsorship was involved in the production of this manuscript.

\section{Conflict of Interest}

The authors report no conflicts of interest.

\section{Acknowledgments}

The authors would like to acknowledge our echocardiography technicians (Ms. Chelsea Tippit and Ms. Catherine Creech) and our pediatric cardiologists (Ashraf M. Aly and Amyn K. Jiwani) for all their help in this study.

\section{References}

1 Jacquemyn Y,Zecic A, Van Laere D, Roelens K. The use of intravenous magnesium in non-preeclamptic pregnant women: fetal/neonatal neuroprotection. Arch Gynecol Obstet 2015;291(05):969-975

2 Nelson KB, Grether JK. Can magnesium sulfate reduce the risk of cerebral palsy in very low birthweight infants? Pediatrics 1995;95 (02):263-269

3 Schendel DE, Berg CJ, Yeargin-Allsopp M, Boyle CA, Decoufle P. Prenatal magnesium sulfate exposure and the risk for cerebral palsy or mental retardation among very low-birth-weight children aged 3 to 5 years. JAMA 1996;276(22):1805-1810

4 Crowther CA, Hiller JE, Doyle LW, Haslam RR; Australasian Collaborative Trial of Magnesium Sulphate (ACTOMg SO4) Collaborative Group. Effect of magnesium sulfate given for neuroprotection before preterm birth: a randomized controlled trial. JAMA 2003;290(20):2669-2676

5 Marret S, Marpeau L, Zupan-Simunek V, et al; PREMAG trial group. Magnesium sulphate given before very-preterm birth to protect infant brain: the randomised controlled PREMAG trial. BJOG 2007;114(03):310-318

6 Rouse DJ, Hirtz DG, Thom E, et al; Eunice Kennedy Shriver NICHD Maternal-Fetal Medicine Units Network. A randomized, controlled trial of magnesium sulfate for the prevention of cerebral palsy. N Engl J Med 2008;359(09):895-905

7 Dice JE, Bhatia J. Patent ductus arteriosus: an overview. J Pediatr Pharmacol Ther 2007;12(03):138-146

8 Jain A, Shah PS. Diagnosis, evaluation, and management of patent ductus arteriosus in preterm neonates. JAMA Pediatr 2015;169 (09):863-872

9 Weisz DE, McNamara PJ, El-Khuffash A. Cardiac biomarkers and haemodynamically significant patent ductus arteriosus in preterm infants. Early Hum Dev 2017;105(105):41-47

10 Mancini MC, Barbosa NE, Banwart D, Silveira S, Guerpelli JL, Leone CR. Intraventricular hemorrhage in very low birth weight infants: associated risk factors and outcome in the neonatal period. Rev Hosp Clin Fac Med Sao Paulo 1999;54(05):151-154

11 Shennan AT, Dunn MS, Ohlsson A, Lennox K, Hoskins EM. Abnormal pulmonary outcomes in premature infants: prediction from oxygen requirement in the neonatal period. Pediatrics 1988;82 (04):527-532

12 Gordon P, Christensen R, Weitkamp J-H, Maheshwari A. Mapping the new world of necrotizing enterocolitis (NEC): review and opinion. EJ Neonatol Res 2012;2(04):145-172

13 Reid S, Bajuk B, Lui K, Sullivan EA; NSW and ACT Neonatal Intensive Care Units Audit Group, PSN. Comparing CRIB-II and SNAPPE-II as mortality predictors for very preterm infants. J Paediatr Child Health 2015;51(05):524-528

14 James AT, Corcoran JD, Hayes B, Franklin O, El-Khuffash A. The effect of antenatal magnesium sulfate on left ventricular afterload and myocardial function measured using deformation and rotational mechanics imaging. J Perinatol 2015;35(11):913-918

15 Paradisis M, Osborn DA, Evans N, Kluckow M. Randomized controlled trial of magnesium sulfate in women at risk of preterm delivery-neonatal cardiovascular effects. J Perinatol 2012;32(09): 665-670 